\title{
The Impact of Mathematical Writing on Students' Metacognition in Applied Algebra Test
}

\author{
Betsy Lee Guat $\operatorname{Poh}^{1} \&$ Lim Chap Sam ${ }^{2}$ \\ ${ }^{1}$ Department of Applied Mathematics, Faculty of Engineering, The University of Nottingham Malaysia Campus, \\ Selangor, Malaysia \\ ${ }^{2}$ School of Educational Studies, University Science Malaysia, Penang, Malaysia \\ Correspondence: Betsy Lee Guat Poh, Faculty of Engineering, The University of Nottingham Malaysia Campus, Jalan \\ Broga, 43500 Semenyih, Selangor Malaysia
}

Received: October 26, 2015

Accepted: November 10, 2015 Available online: November 27, 2015

doi:10.11114/ijsss.v4i1.1219

URL: http://dx.doi.org/10.11114/ijsss.v4i1.1219

\begin{abstract}
Students always use their pens and papers from time to time in their daily routine mathematics lesson to perform activities such as taking notes, performing calculation, doing mathematics assignments or examinations. However, students mainly use writing as a mechanism to demonstrate their computational skills rather than their conceptual thinking. Mathematical writing becomes a powerful learning tool only if it combines language and mathematical algorithm. Thus, this paper intends to explore the impact of mathematical writing on students' metacognition in an applied algebra test. It attempts to examine the metacognitive behavior of three foundation students in engineering and the qualitative data was the participants' take-home test after five weeks of mathematical writing intervention. This paper reports the analysis of these students' writing responses in the test. The findings revealed the quality of the students' metacognition abilities and their mathematical problem solving skills.
\end{abstract}

Keywords: mathematical writing, metacognition, mathematical problem solving

\section{Introduction}

Mathematical writing inevitably plays an essential part in the teaching and learning of mathematics. In the daily routine mathematics lesson, students always use the writing mechanism to perform activities such as taking notes, performing calculation, doing mathematics assignments or examinations. Nevertheless, when students use mathematical writing only to show procedures and algorithms in solving a mathematical problem, it is rather difficult to justify students' understanding of mathematics concepts and diagnose their misconception about mathematics (Steele, 2005). But, if students are asked to write about their actions and reasons in solving a mathematical problem, their responses will definitely exhibit the degree and quality of their mathematical knowledge and skills. Thus, the capacity of mathematical writing should be extended to integrate language and thoughts besides formulae and equations.

The recognition of mathematical writing as a constructive tool in learning mathematics has raised interest among the mathematics education community (Taylor \& Mcdonald, 2007; Karzemi, Fadaee \& Bayat, 2010; Fung, 2010; Bicer, Capraro \& Capraro, 2013). They declare that writing eventually drives the metacognition mechanism. Metacognition is simply defined as the awareness of cognitive process (Kayashima, Inaba \& Mizoguchi, 2004). It is all about being mindful of one's own thinking and learning process when solving a mathematics problem. It is also the impelling mechanism behind successful problem solving (Garofalo \& Lester, 1985). According to Mayer (1998), the absence of metacognition in the problem solving process triggered low level problem solving skills that only managed to solve routine problems. This shows an interconnection between mathematical writing, metacognition and mathematical problem solving skills.

\section{Problem Statement}

The quality of students' work in mathematical problem solving is always a crucial issue. The mathematics curriculum at the pre-tertiary education in Malaysia has been systematically structured to provide opportunities for students to develop mathematical knowledge and problem solving skill throughout their academic years (Malaysian New Integrated Mathematics Curriculum, 2003). Students are obliged to take part in a series of formal and informal mathematics 
assessments that examine their proficiency in mathematics learning. The final results at the public national examinations such as UPSR, PMR, SPM and STPM (Malaysia Education Blueprint 2013-2025) indicates students' pre-requisite background knowledge to be proceeded to the next level of education. The recognition as a talented mathematics student depends on the performance in mathematics subjects at these public national examinations. However, how do these students' grades obtained in the national examination reflect their proficiency in mathematical problem solving?

The prime concern now is the performance of those students who have completed their secondary education and are going to proceed to pre-university education. Parmjit (2009) investigated the conception of 127 college students and their heuristic action in mathematical problem solving. $98.5 \%$ of these participants had obtained an A grade in the national examination for Mathematics. The data indicated that these students' ability to conceptualize and use heuristic approaches to mathematics problem solving were weak. The study concluded that the grade obtained in the national examination did not reflect the students' mathematical knowledge in mathematical problem solving. Various studies have indicated that Malaysian undergraduates have to struggle to think critically and solve real world application problems (Hashim and Hussein, 2003; Konting et al., 2007 cited in Ghadi et al., 2013). Zakaria and Yusoff (2009) examined the algebra problem solving skills among Malaysian matriculation college students. They discovered that the students' problem solving skills in algebra were average. The majority of the students tried to memorize and apply mathematical rules and definition without fully understanding the underlying concepts. A similar study was carried out by Bayat and Tarmizi (2010) to assess the cognitive strategies and algebraic problem solving performance among first year mathematics students who took the algebra course in a public university in Malaysia. The finding indicated that the majority of them were still poor in engaging at a deep level of problem solving skills. The long duration of exposure to rote learning styles and examination-oriented education system at school has somehow shaped these students' mindset about mathematical problem solving (Lim, 2009; Saleh \& Aziz, 2012).

\section{Literature Review}

When teachers utilize mathematical writing as a teaching tool in the mathematics classroom, students automatically engage in metacognition because the writing activities require students to think independently and take responsibility of their own learning apart from writing down formulae and equations (Mayer, Lester \& Pradl, 1983; Banger-Drowns, Hurley \& Wilkinson, 2004). According to Emig (1977), writing is "a unique powerful multi-representative mode of leaning" that involves the coordination of motor control (hand moving the pen), sensory performance (reading using eyes) and cognitive execution (mental processing information). It is a constructive approach that engages students in their intrapersonal communication so that it is fully comprehensible to the things they describe (Pugalee, 2001). The writing output allows students to read and re-read the product of their thinking that increase their self-understanding and concentration (Jurdak \& Zein, 1998; Pugalee, 2001). Thus, writing eventually drives the metacognition mechanism where language and thoughts becomes integrative (Steele, 2005).

With regard to the relationship between writing and problem solving, many researchers have discovered that the use of writing approach to mathematical problem solving helps students to visualize their mathematical thinking in words and to describe their action at each phase of problem solving (Berkenkotter, 1982; Bell \& Bell, 1985; Lester, Garofalo \& Kroll, 1989; Pugalee, 2001). As claimed by Berkenkotter (1982), a writer is a problem solver of a particular task. In an effort to write, writers experience a series of cognitive process and strategic actions or plans to compose a good article or a good report or a good solution. Thus, writing is an act of problem thinking. The function of writing to problem solving assists students to switch back and forth between verbal and visual modes of thoughts.

From a psychological perspective, writing occupies almost the fullest functionality of cognitive, such as analysis and synthesis that unite past, present and future experience to create signification or meaning (Emig, 1977, Oates, 2000). This has corresponded to Fung's (2010) claim that mathematical writing acts as an impelling tool that prompts students through the levels of Bloom's taxonomy. It no longer allows students' mind to be stagnated at the dimension of recalling and remembering but increases their mental power to higher forms of thinking such as applying, analyzing and evaluating. Furthermore, mathematical writing facilitates the role of feedback as well as reinforcement in the learning process and the product of these behaviors is graphically recorded (Emig, 1977, Morgan, 2001). These visible responses assist one to reformulate and reinterpret for generating new knowledge or rectifying the misconception. In general, mathematical writing triggers the internalization of one's cognitive process and the behavior of composing stimulate one to reflect, monitor, revise the process and products of his or her own learning (Pugalee, 2001, Steele, 2005; Fung, 2010; Bicer, Capraro \& Capraro, 2013). This implies that mathematical writing is a conscious and interactive process that allows the transmission of knowledge obtained through action. Thus, this paper reports the analysis of three students' problem solving in an Applied Algebra test in order to explore the impact of mathematical writing on students' metacognition in mathematical problem solving. 


\section{Methodology}

\subsection{Procedure}

Mathematical writing was integrated in the teaching planning in a mathematics course i.e. Applied Algebra as a tool to guide the students in learning mathematics. There were 155 Foundation Students in Engineering enrolled into this module. The lecture and tutorial were conducted in a classroom that was equipped with a visualizer. A visualizer is a real-time image capture device that displays an item to a large audience. With a visualizer, the problem solving process for each mathematic task was demonstrated using the mathematical writing approach while the students watched it on a large screen. The students were also engaged in a prompt writing for ten minutes at the beginning or at the end of each class, twice a week. Besides this, the writing exercises were also integrated into an electronic homework system called Maple TA where the students were encouraged to write outside the classroom. After five weeks of mathematical writing experience in class, the students were required to complete a take-home test. An instruction was given at the first page of the test where the students were required to define the variables they used and to explain their reasoning for their working. They were given one day to complete the test.

\subsection{Analysis of Data}

Three students' problem solving works were purposively selected where their scores for the additional mathematics subject at the public national examination were graded as "A+". In order to rate the students' writing protocols systematically, a coding scheme was developed (see Table 1) and consists of activities that reprsesent the metacognitive behaviors for mathematical problem solving. The scheme was adapted from the work by Pugalee (2001), where he employed Garofalo and Lester's metacognitive framework (1985) and further classified the metacognitive behaviors into sub-categories (see Appendix). The scheme is composed of four phases i.e. orientation, organization, execution and verification that are associated with an individual's problem solving performance. Each phase was judged based on the written expression of students' problem solving work. The orientation phase of problem solving focuses on students' understanding of a problem. It involves the actions of jotting down the main ideas, making sense of the information and identifying key ideas of relevant information for solving the problem. The organization phase reveals students' plans of action. This includes making specific mathematical concepts, facts and algorithms, constructing conjectures and making informed decisions about strategies and approaches. The execution phase concentrates on solving equations and performing calculations while the verification session stresses on any statements or expressions that reveal students' effort of checking the computation or accuracy of their work.

Table 1. Coding Scheme for Writing Protocols Associated with Metacognitve Behaviors during Problem Solving

\begin{tabular}{|c|c|c|c|}
\hline Phase & Activity & & Code \\
\hline \multirow{4}{*}{$\begin{array}{l}\text { Orientation }- \text { related to } \\
\text { assessing and understanding } \\
\text { the problem situation }\end{array}$} & 1) & Jotting down the main ideas; & M1-1 \\
\hline & 2) & Making sense of the information; & M1-2 \\
\hline & 3) & $\begin{array}{l}\text { Identifying key ideas relevant information for solving } \\
\text { the problem; }\end{array}$ & M1-3 \\
\hline & 4) & Relating it to a certain mathematics domain. & M1-4 \\
\hline \multirow{3}{*}{$\begin{array}{l}\text { Organization -focus } \\
\text { students' plan of action }\end{array}$} & 1) & Making informed decision about strategies & M2-1 \\
\hline & 2) & $\begin{array}{l}\text { Making specific mathematical concepts, facts and } \\
\text { algorithms }\end{array}$ & M2-2 \\
\hline & 3) & Organizing data into other formats or drawing diagram & M2-3 \\
\hline \multirow{2}{*}{$\begin{array}{l}\text { Execution }- \text { a monitored } \\
\text { action on plans and } \\
\text { exploration }\end{array}$} & & $\begin{array}{l}\text { Carrying out details of a plan either computing or } \\
\text { analyzing. }\end{array}$ & M3-1 \\
\hline & 2) & $\begin{array}{l}\text { Performing calculation- solving equations and other } \\
\text { manipulations of numeric information }\end{array}$ & M3-2 \\
\hline $\begin{array}{l}\text { Verification }- \text { evaluating } \\
\text { decisions and results }\end{array}$ & $\begin{array}{l}\text { Engag } \\
\text { work }\end{array}$ & n checking the computation/logic or accuracy of & M4 \\
\hline
\end{tabular}

Reliability for data analysis was achieved through an additional reviewer who analyzed ten samples of students' work in problem solving. He played the role of cross-checking the coding process in order to ensure fairness, accuracy and consistency in grading. The researcher and the independent reviewer also discussed the coding of metacognitive components of the students' work in problem solving. This provides greater assurance that judgments are consistent with other peers. 


\section{Results and Discussions}

The take-home test consisted of three vector application problems. The students were given one day to complete the test. The discussion in this section was restricted to one question, as it would be lengthy to discuss the students' responses for all the questions. This problem examined the students' understanding on applying the concept of vector geometry to compute the path taken by two remote control helicopters, as shown below.

Company A is doing an experiment on two high-tech remote control (RC) mini helicopters, T1 and T2 They are travelling together at different locations. At time $\mathrm{t}=0$, they depart and follow different straight-line paths given by

$$
\begin{gathered}
T_{1}: x=3+2 t, \quad y=-1+4 t, \quad z=2+t \\
T_{2}: x=3+2 t, \quad y=2+t, \quad z=-2+2 t
\end{gathered}
$$

Time,t is measured in minutes and all coordinates are measured in meters. Determine whether the two RC mini helicopters are going to collide with each other.

During the flight of $\mathrm{T} 2$, the engine has a malfunction at $(7,4,2)$ and, in a negligible amount of time, it lands at $(7,4,0)$. Five minutes later, $\mathrm{T} 1$ is advised to head toward $\mathrm{T} 2$ at the speed of $5 \mathrm{~m} / \mathrm{min}$. How long will it take for $\mathrm{T} 1$ to reach to T2?

Three students' problem solving works are considered in the following discussion. The actual worksheets of Student A, Student B and Student $C$ attempting to solve the problem are shown in Table 2, 3 and 4 respectively.

The problem solving behavior of Student A showed a smooth path of metacognitive actions, as presented in Table 2. His writing demonstrated his initial attempt to understand the problem by identifying the key ideas of the given information and performing a plan of actions. Subsequently, he executed his plan to compute the intersection point between the paths taken by the two remote control helicopters i.e. $T_{1}$ and $T_{2}$. His responses to look for another " $s$ " value indicated his metacognitive awareness to validate his finding that the two helicopters would not collide with each other. He further coordinated the information given where he managed to compute the location of $T_{1}$ when $T_{2}$ experienced malfunction. With the concept of speed and distance, he found the amount of time $T_{1}$ took to reach its destination. Student A's writing exhibits a systematic approach to the problem and the use of language further gives a comprehensive view of his metacognitive actions.

\begin{tabular}{|c|c|c|c|}
\hline \multicolumn{2}{|l|}{ Written Responses } & Activity & Phase \\
\hline \multirow{2}{*}{\multicolumn{2}{|c|}{$\begin{array}{l}\text { To check whether } 2 \text { helicopters are going to collide with each other, we } \\
\text { can use intersection point of } 2 \text { systems which means both systems will } \\
\text { have same coordinates of } x, y, z\end{array}$}} & $\begin{array}{l}\text { Jotting down the } \\
\text { main ideas, } \\
\text { making sense of } \\
\text { information; }\end{array}$ & Orientation \\
\hline & & $\begin{array}{l}\text { Making informed } \\
\text { decision about } \\
\text { strategies and } \\
\text { approaches. }\end{array}$ & Organization \\
\hline$\therefore 3+2 t=3+2 s \Rightarrow 2 t-2 s=0 \quad---(1)$ & $4 t-4 s=0$ & \multirow{5}{*}{$\begin{array}{l}\text { Making specific } \\
\text { algorithm; } \\
\text { performing } \\
\text { calculation. }\end{array}$} & \multirow[t]{2}{*}{ Organization } \\
\hline$-1+4 t=2+s \Rightarrow 4 t-s=3 \ldots(2)$ & $-4 t-s=3$ & & \\
\hline $2+t=-2+2 s \Rightarrow t-2 s=-4 \ldots .(3)$ & $-3 s=-3 ; s=1$ & & \multirow[t]{3}{*}{ Execution } \\
\hline Solve equation (1) \& (2) & Sub $s=1$ into (2) $4 t-s=3$ & & \\
\hline$(2 t-2 s=0) \times 2$ & $4 t-1=3 ; t=1$ & & \\
\hline
\end{tabular}

Table 2. Analysis of Student A's problem solving work

Use equation (3) to determine whether the system has a solution.

Let $t=1$ and substitute into (3)

$$
\begin{array}{r}
t-2 s=-4 \\
(1)-2 s=-4 \\
s=5 / 2
\end{array}
$$

The s value is different from the answer obtained above which means the system do not intersect therefore they $\left(T_{1} \& T_{2}\right)$ don't collide with each other.
Making informed
decision about
strategies;
Solving equation.
Execution
Engaged in
checking the Verification
logic of the work

Engine mulfunction happens at $(7,4,2)$, how long do $T_{2}$ takes to reach the Making informed Organization




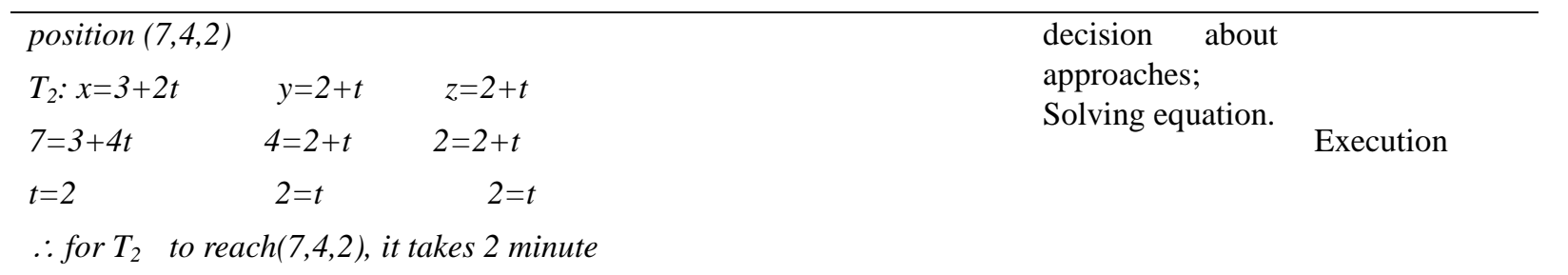

In the question, it stated that five minutes later $T_{1}$ is advised to head
toward $T_{2}$. Therefore we have to check the location of $T_{1}\left(x_{1}, y_{1}, z_{1}\right)$ after 2
minutes of departure plus the 5 minutes which is 7 minutes,

$T_{1}: x=3+2 t \quad y=-1+4 t \quad z=2+t$

$x=3+2(7) \quad y=-1+4(7) \quad z=2+(7)$

$x_{1}=17 \quad y_{1}=27 \quad z_{1}=9$

$\therefore$ the location of $T_{1}$ after 7 minutes is $(17,27,9)$
Identifying key Orientation

ideas relevant information for solving the problem

Making informed decision about approaches;

Organization

Performing

calculation

Execution

$\begin{array}{lll}\text { Identifying key } & \text { Orientation } \\ \text { ideas relevant } & \\ \text { information for } & \\ \text { solving the } & \\ \text { problem; } & & \\ \text { Identifying } & & \\ \text { strategies } & \text { to } & \\ \text { devise a plan. } & & \text { Organization }\end{array}$

$\therefore$ by finding the distance between the 2 positions $(17,27,9)$ and $(7,4,0)$ we can eventually find the time taken for $T_{1}$ to reach $T_{2}$,

devise a plan.

Organization

By using the distance between 2 points

formula: $\quad d=\sqrt{\left(x_{2}-x_{1}\right)^{2}+\left(y_{2}-y_{1}\right)^{2}+\left(z_{2}-z_{1}\right)^{2}}=$

$\sqrt{(7-17)^{2}+(4-27)^{2}+(0-9)^{2}}$

$=26.65 \mathrm{~m}$

Carrying out the

plan by

performing Execution

calculation

The speed of $T_{1}$ to reach $T_{2}$ is $5 \mathrm{~m} / \mathrm{min}$

$$
\therefore \text { time }=\frac{\text { distance }}{\text { speed }}=\frac{26.65}{5}=5.33 \mathrm{~min}
$$

$\therefore$ time taken for $T_{1}$ to reach $T_{2}$ is $5.33 \mathrm{~min}$

Student B's problem solving work is shown in Table 3. The nature of Student B's work showed a purely cognitive action that only involved standard calculation work. There were no data items that indicated his initial understanding of the problem and employing appropriate information. His written description about his mathematical reasoning was brief and only provided evidence of his control mechanism during solution attempt i.e. at the organization and execution phase. Thus, his mathematical writing shows very little evidence of his metacognitive engagement especially at the initial stage of attempting the problem. This can be seen in his work of inconsistency in using the variable $t$. Initially, he used $t$ to define the time where the two helicopters collided with each other. However, he used the same $t$ again to compute the time when $T_{2}$ experienced malfunction and the time taken for $T_{1}$ to reach the location of $T_{2}$. This demonstrates an illogical reasoning in his work. Thus, Student B's writing behavior exhibits his low metacognitive awareness where he did not carefully monitor and check the progress of the computation.

Table 3. Analysis of Student B' problem solving work

\begin{tabular}{cclc}
\hline Written Responses & & Activity & Phase \\
\hline$T_{1}: x=3+2 t$ & $T_{2}: x=3+2 t$ & $\begin{array}{l}\text { Organizing data into Organization } \\
\text { other format }\end{array}$ \\
$y=-1+4 t$ & $y=2+t$ & & \\
$z=2+t$ & $z=-2+2 t$ & Solving equation \\
\hline
\end{tabular}




$\begin{array}{ccc}\mathrm{T}_{1}=\left(\begin{array}{l}-1 \\ 2\end{array}\right)+\mathrm{t}\left(\begin{array}{l}4 \\ 1\end{array}\right) & T_{2}=\underset{y_{T 1}=y_{T 2}}{\left(\begin{array}{c}2 \\ -2\end{array}\right)}+t\left(\begin{array}{l}1 \\ 2\end{array}\right) & \text { Execution } \\ \therefore x_{T 1}=x_{T 2} & 2+t=-2+2 t & \\ 3+2 t=3+2 t & -1+4 t=2+t & t=4\end{array}$

All values of $t$ are not the same. Hence, the helicopter will not collide at any point.

Engage in checking the logic of the work
Verification

$\begin{array}{l}\text { Time for } \\ T_{2}\end{array}$ engine to malfunction at point $\left.<7,4,2\right\rangle$
$\begin{aligned} & 3+2 t=7 \\ & 2 t=4\end{aligned} \quad \begin{aligned} & 2+t=4 \\ & t=2\end{aligned}$
$\therefore$ Since all $t$ is the same, the time for $T_{2}$ engine to malfunction is 2
minutes

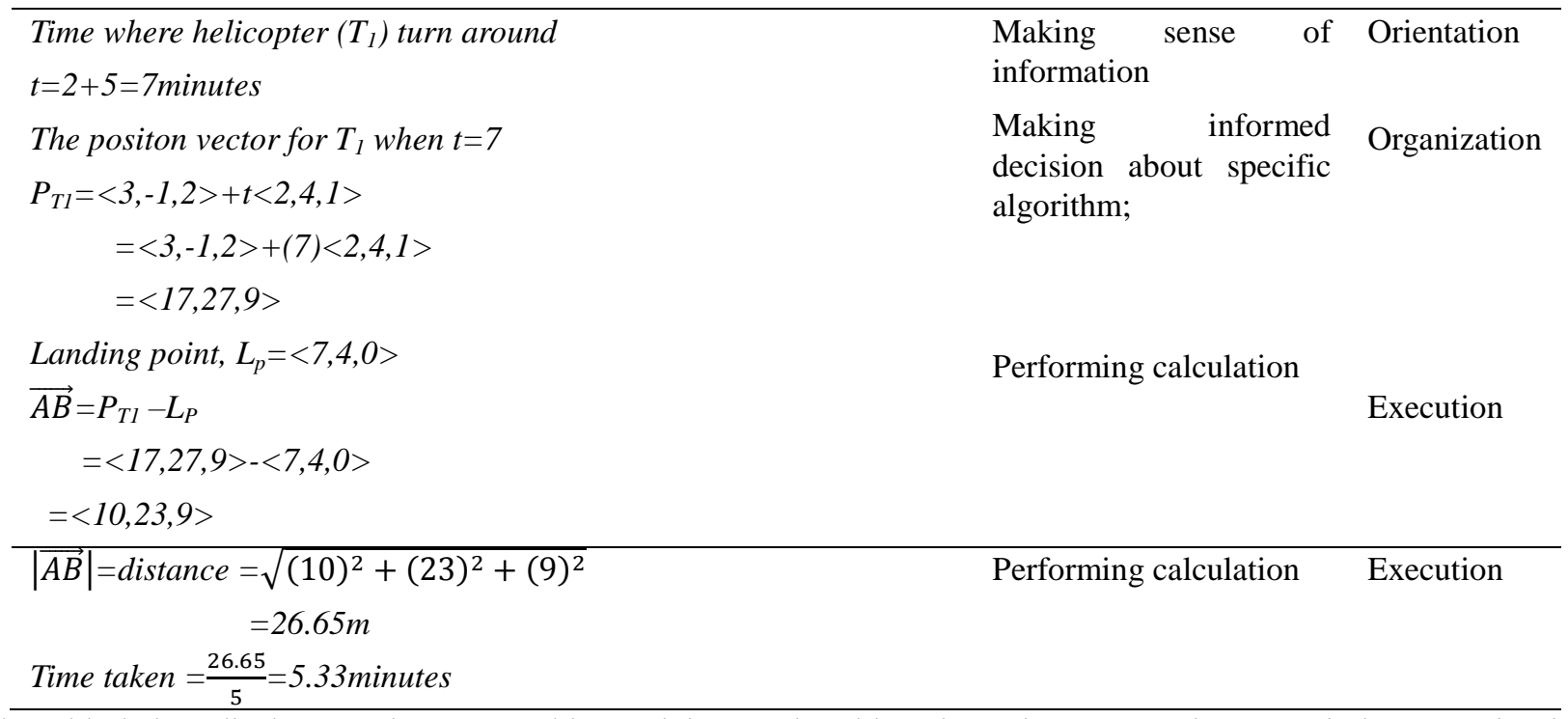

The table below displays Student C's problem solving work. Although Student C's work was entirely presenting her computation techniques, however, it is kind of interesting to note that Student $\mathrm{C}$ tried to use different approach to determine whether the two helicopters were collided with each other. She proved that the path taken by $T_{1}$ and $T_{2}$ were not parallel but unfortunately she didn't connect this concluding section to her next problem solving step. She computed the distinct value of coordinate $y$ between the two helicopters at time $t=4$ and she swiftly concluded that there was no crash between the two helicopters. However, these problem solving steps were not sufficient to support her claim. In fact, if she fully utilized the writing mechanism to drill her logical thinking, she would notice that the paths taken by the two helicopters were actually skew lines. In other word, the two helicopters flew at two different level surfaces.

Table 4. Analysis of Student C's problem solving work

\begin{tabular}{lll}
\hline Written Responses & Activity & Phase \\
\hline$T_{1}=x=3+2 t ; y=-1+4 t ; z=2+t$ & & \\
$T_{2}=x=3+2 s ; y=2+s ; z=-2+5 s$ & Relating it to a Orientation \\
certain & \\
Check parallel: $T_{1}=(2,4,1) \quad$ not parallel & domain. & \\
$T_{2}=(2,1,2)$ & Solving equation & Execution \\
\hline$x=3+2 t=3+2 s, \quad y=-1+4 t=2+s, \quad z=2+t=-2+2 s$ &
\end{tabular}




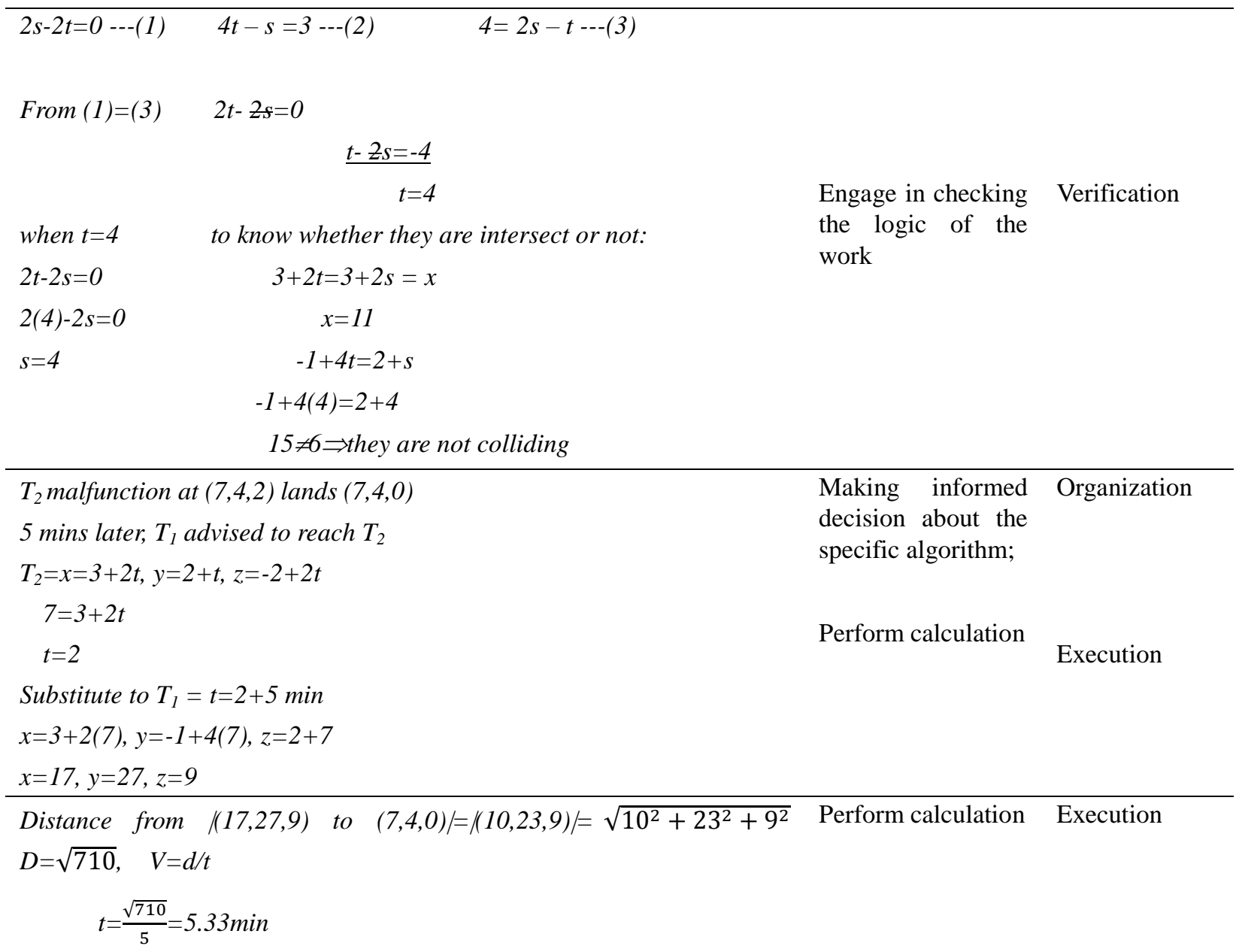

Assessing Student A's problem solving work is like reading a diary of his experience from one mode of thinking to the other. Through mathematical writing, he revealed his hidden thoughts and shared his ideas and solution strategies. His written work was made visible to the reviewer and researcher that he internalized his thinking during the problem solving process. Rating Student B's and Student C's problem solving works are mainly on their calculation process that provides vague responses about their thinking process. Evaluating their work is a tedious job because it is more than simply checking the final answer but trying to be able to assess their problem solving thinking skills. They revealed their strength in computational steps rather than recording their mathematical reasoning Thus, it is like what Ball (1993) stated that "it is difficult to discern what some students know or believe-either because they cannot put into words what they are thinking or because I cannot track what they are saying" (p. 387).

\section{Conclusion}

Mathematical writing is not a static form but can work in many dynamic ways, from a relaxed and casual feature of writing to an intellectual and creative type of writing. It develops the thinking process of doing mathematics (Connonlly, 1989, cited in Baxter, Woodward \& Olson, 2005). It supports and extends the invisible thought process where students get the opportunity to discuss their mathematical thinking and express their feelings and opinions. Students' writing output eventually exhibits their way of approaching a mathematical problem. Reading their written responses helps to understand their cognitive states at the moment of problem solving. The data in this study demonstrate that when students generate their own language and ideas, comprehension is increased. At the same time, the act of mathematical writing triggers the awareness of one's own thinking and learning. This can be seen in Student A's problem solving work. The mathematical writing approach to problem solving somehow assisted Student A to demonstrate his metacognitive actions in a coherent manner. On the other hand, Student B and Student C's problem solving approach circulated around numbers, rules and algorithms and it was not easy to decipher from their responses about their metacognitive actions.

The process of introducing a writing programme in a mathematics class is difficult because it involves restructuring the way students learn, how teachers teach, and also the assessment practices that are normally composed of algorithmic routine computation. However, without a written record of students' thinking, it is difficult to verify and justify their 
metacognition and problem solving achievement. This suggests that mathematical writing should become an integral part of mathematical problem solving to encourage students to vocalize their metacognitive thinking process when they work on a mathematics problem. It is hoped that this study will stimulate more research to further develop the interrelationship between mathematical writing, metacognition and mathematical problem solving.

\section{Acknowledgements}

The work was supported by the Teaching and Learning Funding Scheme from the University of Nottingham Malaysia Campus (UNMC). The authers are grateful to the University for their financial support and for providing necessary guidance in the implementation of this project. The authors also would like to express their sincere thank to Dr. Liew Kian Wah, from UNMC who devoted his time and knowledge in reviewing and checking the coding of the students' work. A special thank goes to Madam Thuzar Winn who read and offered invaluable detailed advices on grammar of this paper.

\section{References}

Ball, D. L. (1993). With an eye on the mathematical horizon: Dilemmas of teaching elementary school mathematics. The elementary school journal, 373-397.

Bangert-Drowns, R. L., Hurley, M. M., \& Wilkinson, B. (2004). The effects of school-based writing-to-learn interventions on academic achievement: A meta-analysis. Review of educational research, 74(1), 29-58.

Baxter, J. A., Woodward, J., \& Olson, D. (2005). Writing in mathematics: an alternative form of communication for academically low-achieving students. Learning Disabilities Research \& Practice, 20(2), 119-135.

Bayat, S., \& Tarmizi, R. A. (2010). Assessing Cognitive and Metacognitive Strategies during Algebra Problem Solving Among University Students. Procedia-Social and Behavioral Sciences, 8, 403-410.

Bell, E. S., \& Bell, R. N. (1985). Writing and mathematical problem solving: Arguments in favor of synthesis. School Science and Mathematics, 85(3), 210-221.

Berkenkotter, C. (1982). 'Writing and Problem Solving', Language Connection: Writing and Reading Across the Curriculum, 33-44.

Bean, J. C., \& Peterson, D. (1998). Grading classroom participation. New directions for teaching and learning, 1998(74), $33-40$.

Bicer, A., Capraro, R. M., \& Capraro, M. M. (2013). Integrating Writing into Mathematics Classroom to Increase Students' Problem Solving Skills. International Online Journal of Educational Sciences, 5(2).

Emig, J. (1977). Writing as a mode of learning. College composition and communication, 122-128.

Fung M. G. (2010). 'Writing in a Mathematics Class? A Quick Report on Classroom Practices at the Collegiate Level', Currents in Teaching and Learning, Teaching Report, 2(2), 22-34

Garofalo, J., Frank K., \& Lester, Jr. (1985) "Metacognition, cognitive monitoring, and mathematical performance." Journal for research in mathematics education (1985), 163-176.

Ghadi, I. N., Bakar, K. A., Alwi, N. H., \& Talib, O. (2013). Measuring Critical Thinking Skills of Undergraduate Students in Universiti Putra Malaysia. International Journal of Asian Social Science, 3(6), 1458-1466.

Hashim, R., \& Hussein, S. (2003). The teaching of thinking in Malaysia. Research Centre, International Islamic University Malaysia.

Hurme, T. R., \& Järvelä, S. (2001). Metacognitive processes in problem solving with CSCL in mathematics. In European perspectives on computer-supported collaborative learning, 301-307.

Jurdak, M., \& Zein, R. A. (1998). 'The Effect of Journal Writing on Achievement in and Attitudes Toward Mathematics', School Science and Mathematics, 98(8), 412-419.

Karzemi, F., Fadaee, M. R., \& Bayat, S. (2010). 'A Subtle View to Metacognitive Aspect of Mathematical Problem Solving', Procedia Social and Behavioral Sciences, 8, 420-426.

Kayashima, M., Inaba, A., \& Mizoguchi, R. (2004). What is metacognitive skill? collaborative learning strategy to facilitate development of metacognitive skill. In World Conference on Educational Multimedia, Hypermedia and Telecommunications, 2004(1), 2660-2665.

Lester, F., Garofalo, J., \& Kroll, D. L. (1989). The role of Metacognition in Problem Solving: A Study of Two Grade Seven Classes. Final Report. Mathematics Education Development Center, School of Education, Indiana University, Bloomington. 
Lim, C. S. (2009). Assessment in Malaysian School Mathematics: Issues and Concerns. 1 - 6. Retrieved from: http://www.criced.tsukuba.ac.ip/math/apec/apec2009/doc/pdf_20-21/LimChapSam-paper.pdf

Mayer, R. (1998). Cognitive, Metacognitive and Motivational Aspect of Problem Solving, Instructional Science, 26, 49-63.

Mayer, J., Lester, N., \& Pradl, G. (1983). Learning to write,writing to learn. Upper Montclair, NJ: Boynton/Cook.

Ministry of Education Malaysia [MOE] (2003a). Mathematics Syllabus for Integrated Curriculum for Primary School. Curriculum Development Centre.

Ministry of Education Malaysia [MOE] (2003b). Mathematics Syllabus for Integrated Curriculum for Secondary School. Curriculum Development Centre.

Ministry of Education Malaysia[MOE] (2012). Preliminary Report Malaysia Education Blue Print 2013-2025.

Morgan, C. (2001). Mathematics and human activity: Representation in mathematical writing. Research in Mathematics Education, 3(1), 169-182.

Oates, L. C. (2000). Beyond Communication: Writing as a Means of Learning. Legal Writing: J. Legal Writing Inst., 6, 1.

Ozsoy, G., \& Ataman. A. (2009). 'The Effect of Metacognitive Strategy Training on Mathematical Problem Solving Achievement', International Electronic Journal of Elementary Education, 1(2), 67-82.

Parmjit, S. (2009). Variation in first year college students' understanding on their conceptions of and approaches to solving mathematical problems. Asian Journal of University Education, 5(1), 95-118

Pugalee, D. K. (2001). Writing, Mathematics, and Metacognition: Looking for Connections Through Students' Work in Mathematical Problem Solving" School Science and Mathematics, 101(5), 236-245

Saleh, S., \& Aziz, A. (2012). Teaching Practices Among Secondary School Teachers in Malaysia. Retrieved from: http://www.ipedr.com/vol47/014-ICERI2012-S00023.pdf

Schneider, W., \& Artelt, C. (2010). Metacognition and mathematics education. ZDM, 42(2), 149-161.

Steele, D. (2005). Using Writing to Access Students' Schemata Knowledge for Algebraic Thinking. School Science and Mathematics, 105(3), 142-154.

Stillman, G., \& Mevarech, Z. (2010). Metacognition research in mathematics education: from hot topic to mature field. $Z D M, 42(2), 145-148$.

Taylor, J. A., \& Mcdonald, C. (2007). 'Writing in Groups as a Tool for Non-Routine Problem Solving in First Year University Mathematics', International Journal of Mathematics Education in Sciennce and Technology, 38(5), 639-655.

Zakaria, E., \& Yusoff, N. (2009). Attitudes and Problem Solving Skills in Algebra Among Malaysian Matriculation College Students. European Journal of Social Sciences, 8(2), 232-249. 


\section{Appendix}

Metacognitive Behavior Associated with Problem Solving Phases, adapted from Garofalo and Lester, 1985

(From Pugalee, 2001)

ORIENTATION: Strategic behavior to assess and understand a problem

- $\quad$ reading/rereading

- initial/subsequent representation

- analysis of information and conditions

- assessment of problem difficulty

ORGANIZATION: Planning of behavior and choice of actions

- identifying goals and subgoals

- making a global plan

- implementing a global plan

- drawing diagrams and organizing data into other formats

EXECUTION: Regulation of behavior to conform to plans

- performing of local goals

- monitoring progress of local and global goals

- performing calculations

- redirecting efforts

VERIFICATION: Evaluation of decisions made and outcomes of executed plans

- evaluating decisions

- checking computation

\section{(cc) EY}

This work is licensed under a Creative Commons Attribution 3.0 License. 